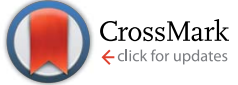

Cite this: J. Mater. Chem. A, 2015, 3, 15616

Received 20th April 2015

Accepted 19th June 2015

DOI: $10.1039 / c 5 t a 02888 d$

www.rsc.org/MaterialsA

\section{Under dark and visible light: fast degradation of methylene blue in the presence of $\mathrm{Ag}-\mathrm{In}-\mathrm{Ni}-\mathrm{S}$ nanocomposites $\uparrow$}

\begin{abstract}
Aniruddha Molla, Meenakshi Sahu and Sahid Hussain*
$\mathrm{Ag}-\mathrm{In}-\mathrm{Ni}-\mathrm{S}$ nanocomposites of different shapes were productively achieved in water using thioacetamide at different temperatures in the presence of SDS with uniform size distributions. It was found that variation of the sodium dodecyl sulphate (SDS) concentration and the temperature had a significant influence on the morphology of $\mathrm{Ag}-\mathrm{In}-\mathrm{Ni}-\mathrm{S}$ and the photocatalytic activity. The newly synthesized $\mathrm{Ag}-\mathrm{In}-\mathrm{Ni}-\mathrm{S}$ nanocomposites were fully characterized by powder XRD, IR, UV-vis, DRS, FE-SEM, TEM, EDX, XPS, BET and TGA. The catalytic activities were measured by the degradation of methylene blue (MB) in the absence and presence of visible light (sunlight and $100 \mathrm{~W}$ tungsten lamp). The catalyst was found to be effective in degrading MB through the generation of reactive oxygen species (ROS) which was confirmed using terephthalic acid (TA), dihydrorhodamine 123 (DHR123) treatment and ESI mass spectroscopy. The removal efficiency of MB by the nanocomposites is very fast, nearly quantitative and repeatable up to five cycles.
\end{abstract}

\section{Introduction}

Many photocatalysts have been attracting a great deal of interest due to their potential applications in the areas of environmental and energy issues. $\mathrm{TiO}_{2}$ (anatase crystal structure) was the first semiconductor photocatalyst discovered in 1972 by Fujishima and Honda. This catalyst was only active under ultraviolet light for the splitting of water on $\mathrm{TiO}_{2}$ electrodes due to its wide band gap (3.0-3.2 eV). ${ }^{1}$ To improve the visible-light sensitivity $(\lambda>400$ $\mathrm{nm})$ of $\mathrm{TiO}_{2}$ photocatalysts, much work has been done. ${ }^{2}$ Most modified and doped photocatalysts have shown low activities, poor absorption of visible light and relatively poor stability during the photocatalytic process. To overcome such limitations, many composites, such as metal oxide/ $\mathrm{TiO}_{2},{ }^{3}$ metal oxide/ metal oxide, ${ }^{4}$ metal/metal halides, ${ }^{5}$ chalcogenides ${ }^{6}$ and graphene-based $^{7}$ composites with heterojunction structure, have been reported. Coupling of two or more chalcogenide materials with different band gaps has been demonstrated to be a practical approach for improving the photocatalytic activity. ${ }^{6}$

Owing to their interesting physical and chemical properties, metal chalcogenides have found various potential technological applications in energy conversion, fuel cells, ${ }^{\mathbf{8}}$ solar cells, ${ }^{\mathbf{}}$ sensors, light-emitting diodes, ${ }^{\mathbf{1 0}}$ Li-ion batteries, photoelectrochemical water splitting, ${ }^{11}$ supercapacitors, ${ }^{12}$ thermoelectric and memory devices. ${ }^{6}$ Silver and silver-doped compounds have been of immense interest over the last few

Department of Chemistry, Indian Institute of Technology Patna, Patna 800 013, India. E-mail: sahid@iitp.ac.in; Fax: +91-612-227-7383; Tel: +91-612-255-2022

$\dagger$ Electronic supplementary information (ESI) available. See DOI: $10.1039 / \mathrm{c} 5 \mathrm{ta} 02888 \mathrm{~d}$ years due to their high photocatalytic activities. ${ }^{13}$ Of late, several photocatalysts have been reported, but only a few were active under visible light because of the catalysts' low visible light utilization and the high recombination rate of photo-induced electron-hole pairs. ${ }^{14}$ Several painstaking strategies have been used to improve upon the light absorption efficiency through doping with non-metal anions and transition metal cations, surface modification with ligands, and noble metals or polymer supports. In terms of modification with noble metals, $\mathrm{Ag}$ is one of the most appropriate candidates for industrial applications because Ag nanoparticles have electron storage properties and they provide a suitable pathway for the transfer of photogenerated charges. ${ }^{\mathbf{1 5}}$ Due to these interesting features, researchers have attempted to synthesize these mixed multinary chalcogenides in a facile, convenient, eco-friendly and costeffective manner. Such mixed multinary chalcogenide composites with different shapes and sizes, can be effective in reducing the recombination probability of photogenerated electrons and holes and have been widely employed to improve the photocatalytic activity.

There are several liquid-phase synthesis methods available, e.g. liquid exfoliation, hot-injection, hydrothermal, solvothermal, microwave, sonochemical, template-directed and colloidal methods, for the production of this type of material. Recently, Huang et al. reported CuS caved superstructures ${ }^{\mathbf{1 6}}$ and their application to the catalysis of organic dye degradation in the absence of light but in the presence of hydrogen peroxide. Some of the reported methods are creditable, but most suffer from drawbacks like the requirement for a special set-up for maintaining inert conditions, high temperatures and low dye removal efficiency with longer times. Herein we report a green 
synthesis of $\mathrm{Ag}-\mathrm{In}-\mathrm{Ni}-\mathrm{S}$ nanocomposites in water using thioacetamide at different temperatures. Modification of the surface with variation of SDS concentration at different temperatures was also performed. The synthesized Ag-In-Ni-S nanocomposites have high catalytic activity and could be applicable for the management of dye polluted waste water purification in the presence and absence of light. ${ }^{13}$

\section{Experimental}

\subsection{Material}

Silver acetate dihydrate $\left[\mathrm{Ag}(\mathrm{OAc}) \cdot 2 \mathrm{H}_{2} \mathrm{O}\right]$, indium acetate $\left[\mathrm{In}(\mathrm{OAc})_{3}\right]$, nickel acetate tetrahydrate $\left[\mathrm{Ni}(\mathrm{OAc})_{2} \cdot 4 \mathrm{H}_{2} \mathrm{O}\right]$, sodium dodecyl sulphate (SDS), thioacetamide $\left(\mathrm{C}_{2} \mathrm{H}_{5} \mathrm{NS}\right)$, ethanol $(\mathrm{EtOH})$ and methylene blue were all analytical grade and used without further purification. Double distilled water was employed throughout the experiments.

\subsection{Catalyst preparation at different reaction conditions with variation of SDS concentration}

In order to synthesize the $\mathrm{Ag}-\mathrm{In}-\mathrm{Ni}-\mathrm{S}$ nanocomposites, silver acetate $(1.0 \mathrm{mmol})$, indium acetate $(1.0 \mathrm{mmol})$, nickel acetate tetrahydrate $(1.0 \mathrm{mmol})$ and SDS (0.1-1.5 mmol) were dissolved in $10 \mathrm{~mL}$ water (solution A). In a separate flask, thioacetamide (3.5 mmol) was dissolved in $5 \mathrm{~mL}$ of water (solution $\mathrm{B}$ ).

Method 1. For hydrothermal synthesis, both solutions A and B were transferred in to $25 \mathrm{~mL}$ Teflon lined sealed stainless steel autoclaves and placed in a preheated oven at $130^{\circ} \mathrm{C}$ for $2 \mathrm{~h}$, before being allowed to cool to room temperature. A black solid precipitate was obtained by centrifugation followed by washing with deionized water ( 5 times) and ethanol ( 3 times) and finally drying under vacuum for $2 \mathrm{~h}$.

Method 2. The temperature of the prepared solution A was raised to $80^{\circ} \mathrm{C}$ and solution $\mathrm{B}$ was added dropwise under continuous stirring for two hours. It was then allowed to cool to room temperature. The obtained black product was collected similarly as in Method 1. Details of the samples are in Table S1, ESI.†

\subsection{Degradation of methylene blue}

In order to evaluate the degradation activities of the prepared $\mathrm{Ag}$ In-Ni-S nanocomposites, the decomposition of methylene blue (MB) in the absence and presence of visible light (sunlight and $100 \mathrm{~W}$ tungsten lamp) was investigated. $20 \mathrm{mg}$ Ag-In-Ni-S was dispersed in $14 \mathrm{~mL}$ aqueous solution of $\sim 10^{-5}$ (M) MB. The suspensions were magnetically stirred in the dark. At given time intervals, $2 \mathrm{~mL}$ aliquots were taken and were centrifuged to remove the catalyst. UV-vis spectra were recorded with $1: 1$ dilution of the experimental solution taken at certain intervals. Blank experiments were also performed under identical conditions.

\section{Characterization of catalysts}

IR spectra were recorded in $\mathrm{KBr}$ on a Shimadzu IR Afinity1. SEM images were obtained from a Hitachi S-4800 microscope at an operating voltage of $15 \mathrm{kV}$. The sample was coated with platinum

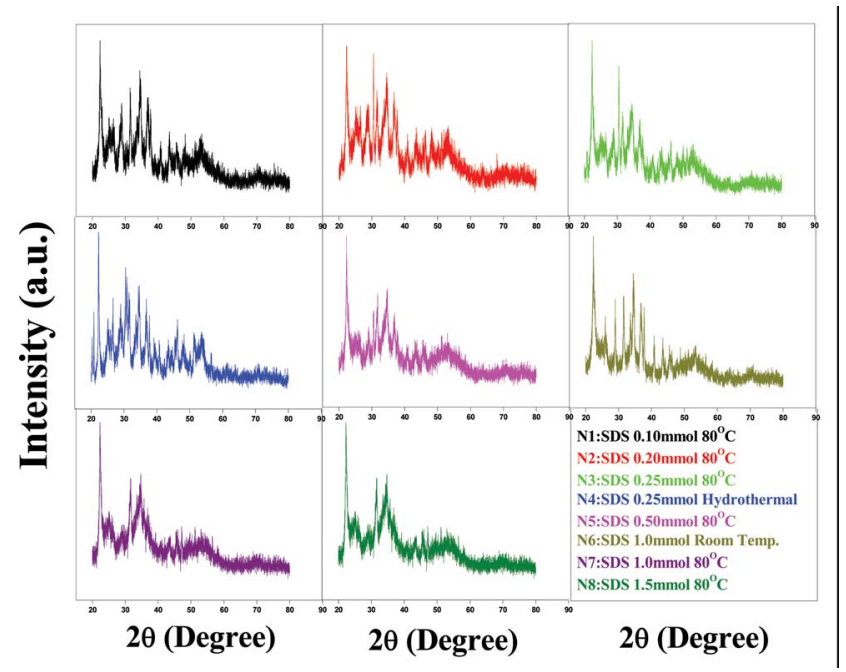

Fig. 1 P-XRD of $\mathrm{Ag}-\mathrm{In}-\mathrm{Ni}-\mathrm{S}$ prepared at various temperatures and SDS concentrations.

for effective imaging before being charged. TEM images were obtained from a JEOL instrument using a Cu grid. UV-vis + DRS and fluorescence data were recorded using a UV-vis spectrophotometer (Shimadzo UV-2550) using standard $1 \mathrm{~cm}$ quartz cuvettes and a Fluoromax-4 spectrofluorometer (Horiba Jobin YVON) respectively. X-ray powder diffraction study was carried out on a Rigaku X-ray diffractometer at a voltage of $10 \mathrm{kV}$ using $\mathrm{Cu} \mathrm{K} \alpha$ radiation $(\lambda=0.15418 \mathrm{~nm})$ at a scanning rate of $0.50^{\circ}$ per minute in the $2 \theta$ range $10-80^{\circ}$. Surface analysis by XPS is accomplished by irradiating a sample with monoenergetic soft $\mathrm{X}$-rays, $\mathrm{Mg} \mathrm{K} \alpha(1253.6 \mathrm{eV})$ using the ESCA probe TPD system in an ultra-high vacuum system. TGA experiments were carried out using a SDT Q600. BET measurements were performed using a Smart Instruments Smart Sorb 92/93.

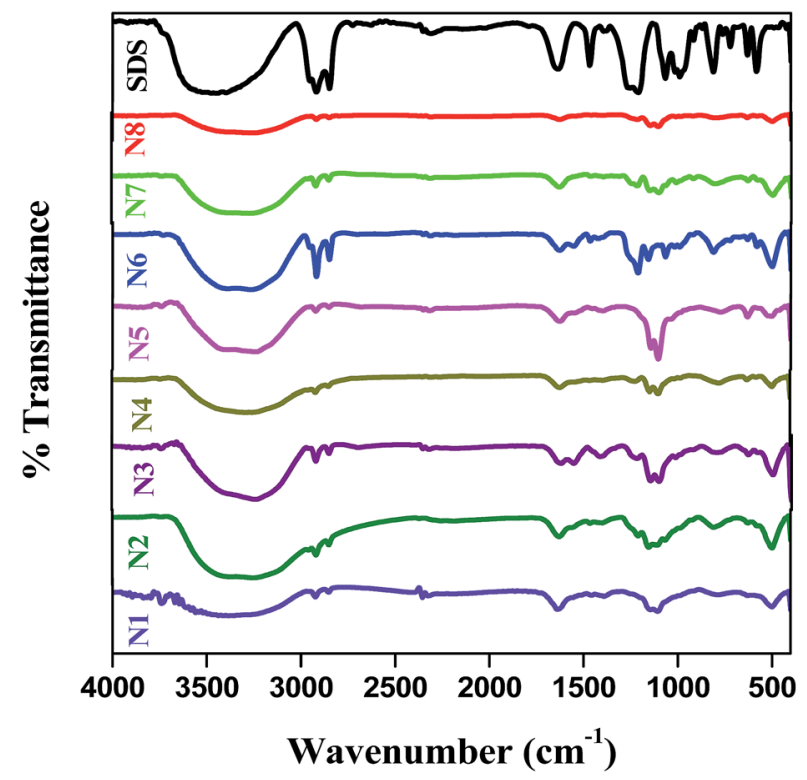

Fig. 2 IR spectra of $\mathrm{Ag}-\mathrm{In}-\mathrm{Ni}-\mathrm{S}$ prepared at various temperatures and SDS concentrations. 


\subsection{X-ray diffraction (XRD)}

Powder XRD patterns of the Ag-In-Ni-S nanocomposites prepared at different temperatures with SDS concentration variation are shown in Fig. 1. The XRD patterns reveal that the samples are composites of binary and ternary chalcogenides. On comparison with the patterns of the individual metal sulphides, it can be seen that samples N1, N2, N3 and N4 are $\mathrm{AgInS}_{2}$-rich and $\mathrm{In}_{2} \mathrm{~S}_{3}$-rich. When the synthesis was carried out at room temperature (N6), mostly individual metal sulphides were formed. Samples N5 and N7 show similar types of diffraction peaks. For N8, the weak and diffuse peaks at $(2 \theta)$ $56-60^{\circ}$ are mainly due to binary chalcogenides $\left(\mathrm{Ag}_{2} \mathrm{~S}, \mathrm{NiS}_{2}\right.$ and $\mathrm{In}_{2} \mathrm{~S}_{3}$ ) whereas the intense peaks located at 28.43, 43.9, 48.0 and $53.44^{\circ}$ are due to the presence of a combination of binary and ternary chalcogenides. On comparison of the XRD patterns of all samples (ESI, Fig. S1†) it was found that the temperature had a significant influence on the formation of binary and ternary chalcogenides. At relatively low
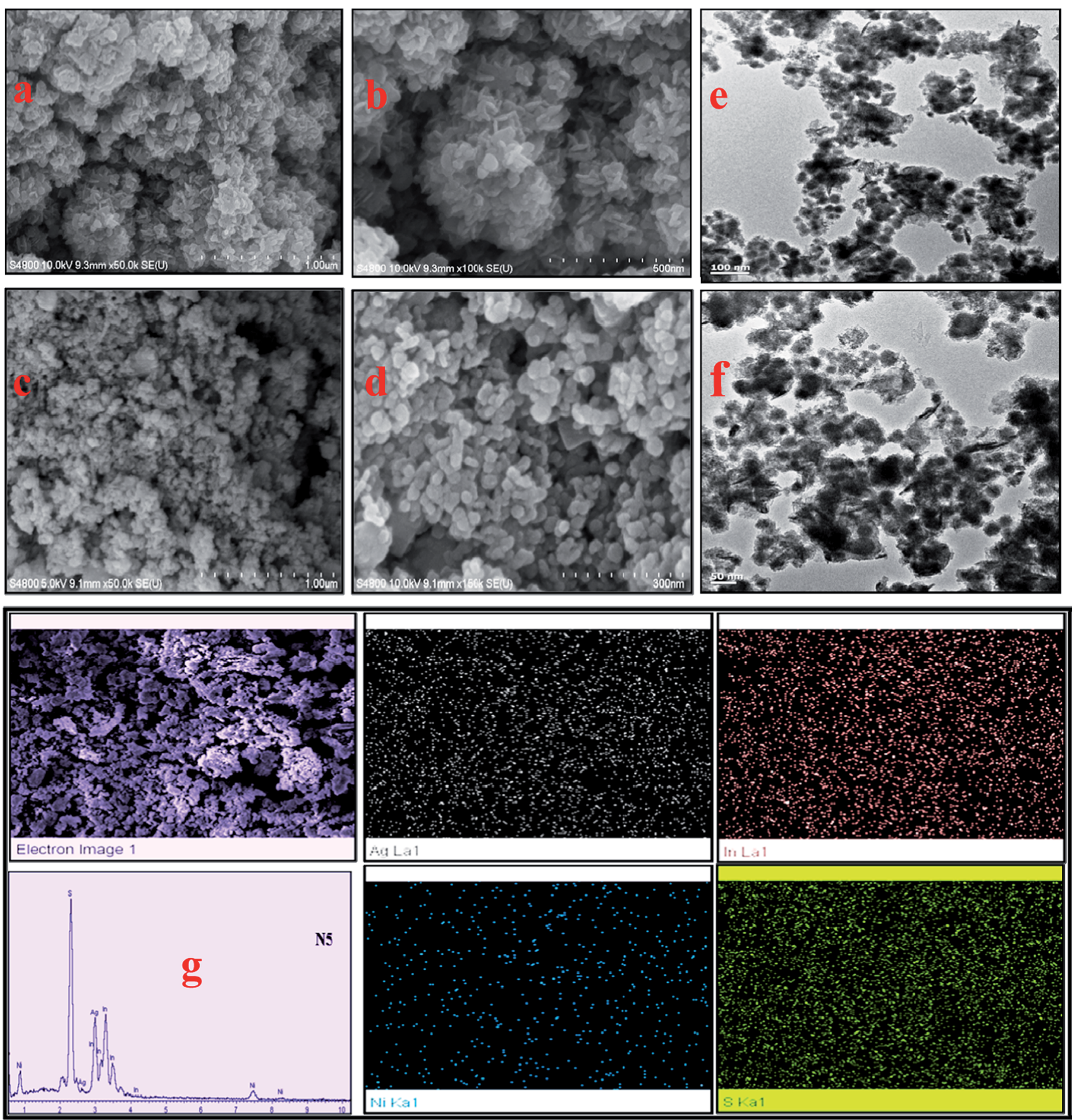

Fig. 3 Morphological study of Ag-In-Ni-S prepared at $80{ }^{\circ} \mathrm{C}$ (samples N5 and N8). (a) Low magnification FE-SEM image of N5, (b) FE-SEM image of N5 at $500 \mathrm{~nm}$, (c) low magnification FE-SEM image of N8, (d) FE-SEM image of N8 at $300 \mathrm{~nm}$, (e) low magnification TEM image of N5, (f) TEM image of N5 at $50 \mathrm{~nm}$, (g) EDX spectra of N5 with elemental and line scan. 
temperatures, binary chalcogenide formation is more favourable than multinary chalcogenides. ${ }^{17}$ Detailed quantitative analysis results (RIR) for N8 are reported in Table S2, ESI. $\dagger$ It is also understandable from the XRD patterns that the different concentrations of SDS help the formation of individual metal sulphides differently.

\subsection{Infrared spectroscopy (FT-IR)}

FT-IR spectra of all the produced Ag-In-Ni-S nanocomposites are shown in Fig. 2. All the samples show peaks at $\sim 3250-$ $3350,1640,1200$ and $800 \mathrm{~cm}^{-1}$. A weak metal-sulphur band can be seen in the spectrum in the range $550-400 \mathrm{~cm}^{-1}$ together with the surface bonded SDS characteristic peaks in the regions of $1500-1000$ and $3200-3400 \mathrm{~cm}^{-1}$. A peak shift was observed for all the samples when compared to blank SDS. This might be due to surface interaction of SDS with the samples.

\subsection{The morphologies of Ag-In-Ni-S using FE-SEM}

The morphologies of the Ag-In-Ni-S nanocomposites were then studied using FE-SEM. Samples N5 and N8 are used as examples to present the morphology. Both samples show uniform distributions of nanoclusters (Fig. 3a). At higher magnification, a large number of particles of nearly identical shape and size are observed (Fig. 3b-f). N1, N2 and N3, prepared at $80{ }^{\circ} \mathrm{C}$ using SDS $\leq 0.25 \mathrm{mmol}$, show uniform distributions of identical nanospheres (ESI, Fig. S2a-c $\dagger$ ). These nanospheres are converted to a network type structure (N4) when synthesized under hydrothermal conditions at $130{ }^{\circ} \mathrm{C}$ (ESI, Fig. S2d and e $\dagger$ ). Sample N6 prepared at room temperature shows mixed morphology (ESI, Fig. S2f and $g \dagger$ ). Upon increasing the SDS concentration, the spheres are converted to flake-like structures (Fig. 3, N5 and N8). The EDX results of all the samples confirmed that Ag, In, Ni and $\mathrm{S}$ were present in the nanocomposites (Fig. S3, ESI $\dagger$ ). To advance our study, the spatial regularity of the elemental distribution of N5 was measured and the composition was found to be $\mathrm{AgIn} \operatorname{In}_{1.05} \mathrm{Ni}_{0.53} \mathrm{~S}_{2.66}$ (ESI, Table S3 $\dagger$ ). The EDX elemental mapping and line scanning further indicated the homogeneous distribution of $\mathrm{Ag}$, In, $\mathrm{Zn}$ and $\mathrm{S}$ elements throughout the whole sample (Fig. 3g).

\subsection{X-ray photoelectron spectroscopy (XPS) study}

In order to determine the valence states of the constituent elements, sample N8 was examined by X-ray photoelectron spectroscopy (XPS). XPS spectra of Ag-In-Ni-S nanocomposites are shown in Fig. 4. The valence states of $\mathrm{Ag}$, In and $\mathrm{Ni}$ were determined as $\mathrm{Ag}^{+}, \mathrm{In}^{3+}$ and $\mathrm{Ni}^{2+}$ respectively, according to their peak splitting values which were assigned as $377.3\left(3 \mathrm{~d}_{5 / 2}\right)$ and $383.4\left(3 \mathrm{~d}_{3 / 2}\right)$ for $\mathrm{Ag} ; 454.3\left(3 \mathrm{~d}_{5 / 2}\right)$ and $461.8\left(3 \mathrm{~d}_{3 / 2}\right)$ for In; 862.1 $\left(2 \mathrm{p}_{3 / 2}\right)$ and $879.7 \mathrm{eV}\left(2 \mathrm{p}_{1 / 2}\right)$ for $\mathrm{Ni}$ from the fitting data. The two peak of $S, 171.9\left(2 \mathrm{p}_{3 / 2}\right)$ and $178.7\left(2 \mathrm{p}_{1 / 2}\right)$, suggest that it has sulphide states. The wide range (172-179 eV) of sulphide clearly indicates that the nanocomposite is composed of both binary and ternary chalcogenides.
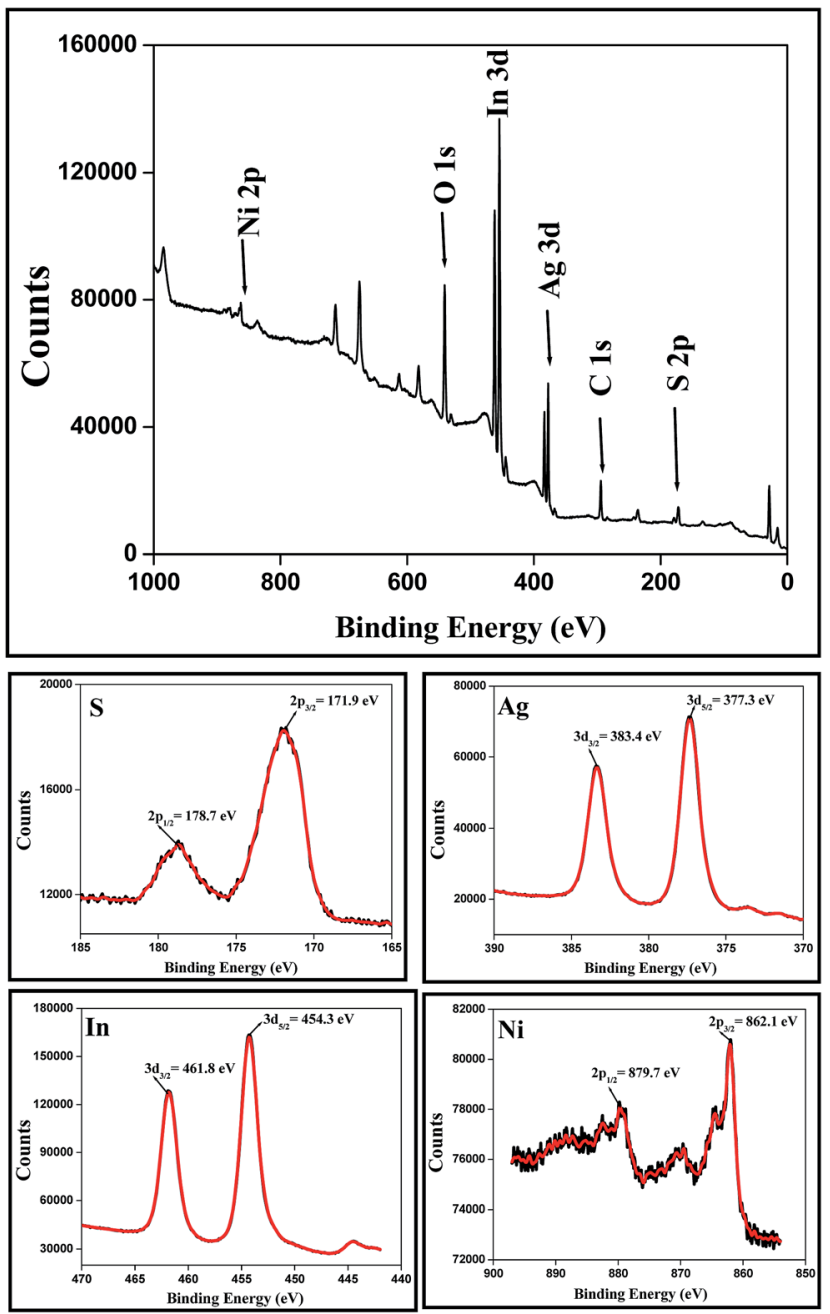

Fig. 4 XPS spectra of $\mathrm{Ag}-\mathrm{In}-\mathrm{Ni}-\mathrm{S}$ nanocomposites.

\subsection{Spectral study of $\mathrm{Ag}-\mathrm{In}-\mathrm{Ni}-\mathrm{S}$}

For UV-vis study, $1 \mathrm{mg}$ of each prepared sample was dispersed in $10 \mathrm{~mL}$ water under sonication. All eight samples give similar spectra (Fig. 5). There is no characteristic peak observed. From the UV-vis spectra, the direct band gap was measured with the help of this power equation ${ }^{\mathbf{1 8}}$ versus photon energy $(h \nu)$ :

$$
(\varepsilon h \nu)^{n}=k_{\mathrm{d}}\left(h \nu-E_{\mathrm{g}}\right)
$$

where $k_{\mathrm{d}}$ is the absorption constant for a direct transition, $n$ is 2 for a direct transition, $h \nu$ is the absorption energy, and $E_{\mathrm{g}}$ is the band-gap energy.

Fig. 6 shows the $(\varepsilon h \nu)^{2}$ versus $h \nu$ curves of samples $\mathbf{N} 5$ and N8, where $\varepsilon$ is the absorbance coefficient, $h$ the Planck constant and $\nu$ the frequency. The direct band gaps $\left(E_{\mathrm{g}}\right)$ of $\mathbf{N 5}$ and $\mathbf{N 8}$ were found to be $1.77 \mathrm{eV}$ and $2.11 \mathrm{eV}$ respectively.

Diffuse reflectance spectroscopy (DRS) was carried out taking barium sulphate as reference (Fig. 7). Almost all the samples exhibit high absorption in the UV-visible region (200-800 nm). The absorption edges at $510 \mathrm{~nm}$ and $496 \mathrm{~nm}$ were found for samples 


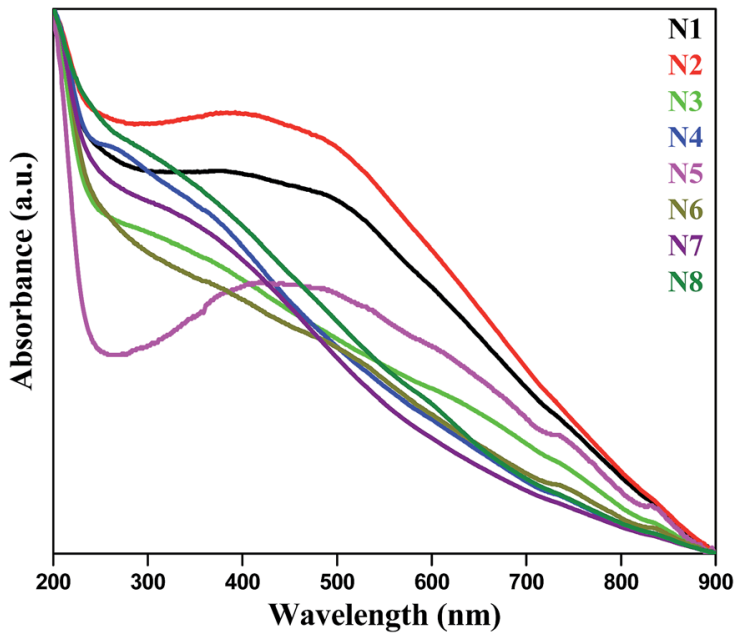

Fig. 5 UV-vis spectra of prepared $\mathrm{Ag}-\mathrm{In}-\mathrm{Ni}-\mathrm{S}$ samples.

N7 and N8 respectively. This result further confirmed our observation that these composites may be suitable candidates for photocatalysis under visible light.

\subsection{BET measurement: surface area analysis}

The nitrogen adsorption-desorption isotherms were measured using a Smart Instrument, Model no-Smart Sorb 92/93, to determine the surface area of the Ag-In-Ni-S nanocomposites. For this measurement samples were regenerated at $250{ }^{\circ} \mathrm{C}$ for two hours. Experiments were performed using a $\mathrm{N}_{2}$ (30\%) and $\mathrm{He}(70 \%)$ mixture. N3, N5 and N8 show surface area values of 29.57, 43.58 and $60.97 \mathrm{~m}^{2} \mathrm{~g}^{-1}$ respectively. From these results, it is clear that with the increase in SDS concentration, the surface area of the nanocomposites increases. The increase in surface area is believed to increase the catalytic activity of the nanocomposites.

\subsection{Thermogravimetric analysis (TGA)}

The thermal stability of the Ag-In-Ni-S nanocomposites was measured using TGA (Fig. 8). All samples were heated to $750{ }^{\circ} \mathrm{C}$

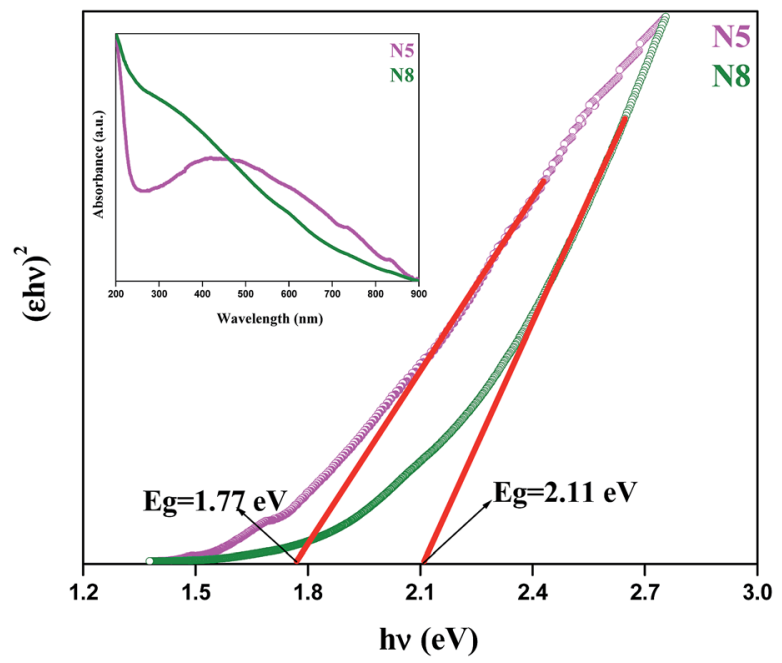

Fig. $6(\varepsilon h \nu)^{2}$ versus $h \nu$ curves of $\mathrm{Ag}-\mathrm{In}-\mathrm{Ni}-\mathrm{S}$ (samples N5 and N8).

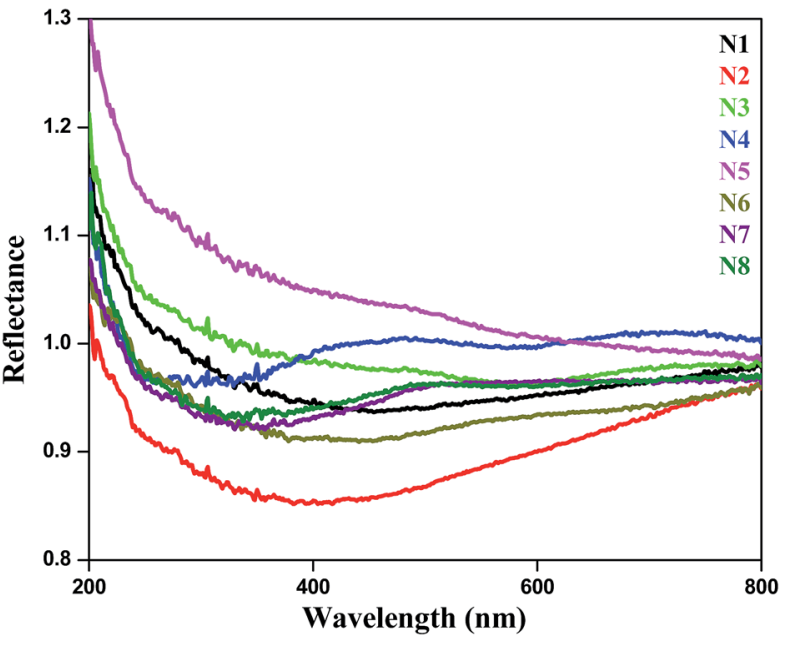

Fig. 7 DRS reflectance spectra of $\mathrm{Ag}-\mathrm{In}-\mathrm{Ni}-\mathrm{S}$ samples.

with a heating rate of $10^{\circ} \mathrm{C} \mathrm{min}^{-1}$. The initial weight loss below $200{ }^{\circ} \mathrm{C}$ is due to the loss of physisorbed moisture. The second weight loss step occurred between $210{ }^{\circ} \mathrm{C}$ and $220^{\circ} \mathrm{C}$ and the third weight loss step occurred between $270{ }^{\circ} \mathrm{C}$ and $287^{\circ} \mathrm{C}$. The $2^{\text {nd }}$ and $3^{\text {rd }}$ step decay indicates the weight loss due to organics (surface bonded SDS) whereas the decay above $450{ }^{\circ} \mathrm{C}$ might be due to sublimation of metal sulphides. As evident from the TGA curves, N8 shows maximum stability while N5 is the least stable.

\subsection{Degradation of methylene blue}

$\mathrm{MB}$, a stable dye, has a characteristic absorption band at 663 $\mathrm{nm}$, which is employed to assess the degradation of Ag-In-Ni-S nanocomposites. Optimization of catalyst loading in the presence of different amounts of $\mathbf{N 8}(1 \mathrm{mg}, 5 \mathrm{mg}, 10 \mathrm{mg}, 15 \mathrm{mg}$ and $20 \mathrm{mg}$ ) was performed (Fig. 9a) in dark conditions. During the initial stage of the study in the presence of $1 \mathrm{mg}$ N8, only $60 \%$ degradation was achieved. $70 \%$ and $86 \% \mathrm{MB}$ was consumed when the degradation was performed with $5 \mathrm{mg}$ and $10 \mathrm{mg}$ of

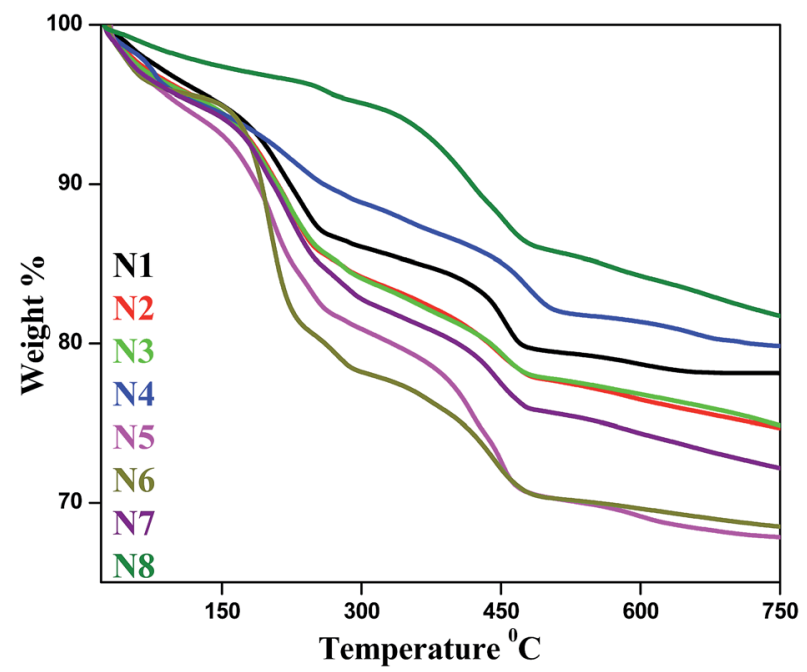

Fig. 8 Thermogravimetric analysis of prepared $\mathrm{Ag}-\mathrm{In}-\mathrm{Ni}-\mathrm{S}$. 

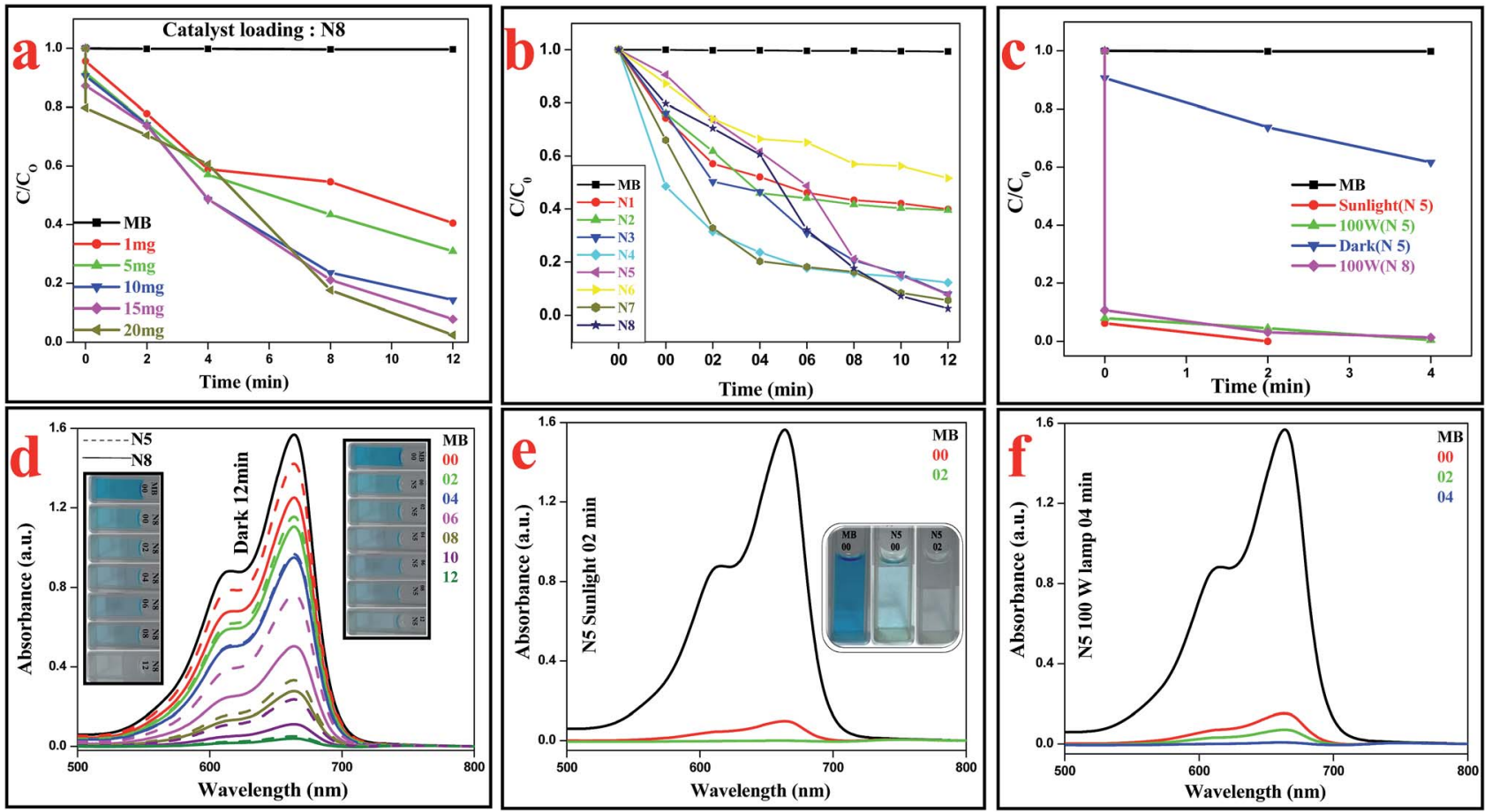

Fig. 9 (a) Catalyst loading of N8, (b) relative concentrations of MB with progress of time, (c) fate of MB in the presence of N5 under various reaction conditions, (d) time dependent UV-vis plot of MB in the presence of N8 and N5, (e) MB with N5 under sunlight, (f) MB with N5 under a 100 W lamp.

N8. Upon increasing the catalyst loading to $15 \mathrm{mg}$, the decomposition rate increased to $92 \%$. On further increase of the catalyst loading to $20 \mathrm{mg}$, almost quantitative degradation took place in $12 \mathrm{~min}$ in dark conditions. All the reactions were performed using the above optimized conditions. As shown in Fig. S4a (ESI), $\dagger$ the concentrations of MB remain almost constant (99.4\%) throughout the experiment in the absence of catalyst. In order to check the efficacy, we started our experiment with N1-N7. N1 and N2 show slow decomposition of MB (ESI, Fig. S4b and c $\dagger$ ) whereas N3, N4, N5 and N7 show moderate to good catalytic activities (ESI, Fig. S4d-h†). Among all of the samples, $\mathbf{N} \mathbf{6}$ is found to have the least decomposition ability (ESI, Fig. S4g $\dagger$ ) whereas $\mathbf{N 8}$ has the highest catalytic activity and almost $98 \% \mathrm{MB}$ is decomposed within $12 \mathrm{~min}$ of reaction in dark conditions (Fig. 9d). The colour changes from blue to colourless also confirm our observation (inset, Fig. 9d). N5 and N8 were also found to be equally effective for Nile blue under a $100 \mathrm{~W}$ lamp (ESI, Fig. S5a-c $\dagger$ ).

When the same set of reactions was performed under incandescent light and in sunlight in the presence of $\mathbf{N 5}$ and N8, very fast degradation of MB was observed. N5 and N8 under a $100 \mathrm{~W}$ lamp consumed MB almost quantitatively with a slightly longer time (4 min) compared to sunlight $(2 \mathrm{~min})$. The variations of methylene blue concentration $\left(C / C_{0}\right)$ with time over different catalysts are given in Fig. $9 \mathrm{~b}$, where $C_{0}$ is the initial $\mathrm{MB}$ concentration before reaction and $C$ is the $\mathrm{MB}$ concentration at time $t$. It is evident from Table 1 and Fig. S6a (ESI $\dagger$ ) that the degradation of MB in the presence of catalysts is

Table 1 Degradation of methylene blue in the presence of prepared $\mathrm{Ag}-\mathrm{In}-\mathrm{Ni}-\mathrm{S}$ catalysts

\begin{tabular}{|c|c|c|c|c|c|c|}
\hline \multirow[b]{2}{*}{ Entry } & \multirow[b]{2}{*}{ Catalyst } & \multirow[b]{2}{*}{$C_{t=4} \min$} & \multirow[b]{2}{*}{$C_{t=10 \mathrm{~min}}$} & \multirow[b]{2}{*}{$C_{0}$} & \multicolumn{2}{|c|}{ Rate constant $\left(\mathrm{min}^{-1}\right)$} \\
\hline & & & & & $t=4 \min$ & $t=10 \mathrm{~min}$ \\
\hline 1 & N1 & 0.818 & 0.661 & 1.569 dark conditions & 0.16283 & 0.08644 \\
\hline 2 & $\mathbf{N} 2$ & 0.722 & 0.633 & & 0.19404 & 0.09077 \\
\hline 3 & N3 & 0.730 & 0.243 & & 0.19128 & 0.18651 \\
\hline 4 & N4 & 0.371 & 0.225 & & 0.36049 & 0.19420 \\
\hline 5 & N5 & 0.967 & 0.235 & & 0.12099 & 0.18986 \\
\hline 6 & N6 & 1.043 & 0.882 & & 0.10208 & 0.05760 \\
\hline 7 & N7 & 0.318 & 0.131 & & 0.39903 & 0.24829 \\
\hline 8 & N8 & 0.951 & 0.112 & & 0.12516 & 0.26396 \\
\hline 9 & N5 $(100 \mathrm{~W})$ & $0.071(2 \mathrm{~min})$ & & 1.569 visible light & 1.547 & \\
\hline 10 & N8 $(100 \mathrm{~W})$ & $0.049(2 \mathrm{~min})$ & & & 1.733 & \\
\hline
\end{tabular}


a pseudo-first order reaction and it follows the trend N8 $>$ N7 $>$ $\mathbf{N} 5 \sim \mathbf{N} 3>\mathbf{N 4}>\mathbf{N} 2 \sim \mathbf{N 1}>\mathbf{N 6}$. A comparative study of decomposition activity for N5 and N8 (Fig. 9c) under various conditions confirmed that $\mathbf{N 5}$ and $\mathbf{N 8}$ are very active catalysts under visible light as well under dark conditions.

\subsection{Towards mechanistic study}

While designing the catalyst, it was thought that the degradation of organic dye would occur via radical formation. An electron paramagnetic resonance (EPR) study showed that the catalyst is "EPR-silent" because it is a non-Kramers system. ${ }^{\mathbf{1 9}}$ Direct detection of reactive oxygen species (ROS) is not feasible due to their very short lifetime. Therefore, indirect measurement of ROS was performed using terephthalic acid (TA) and non-fluorescent dihydrorhodamine 123 (DHR123). ${ }^{20}$ TA is a non-fluorescent compound which upon reaction with $\mathrm{OH}$ radical is converted to fluorescent 2-hydroxyl terephthalic acid (HTA). The gradual increase in fluorescence intensity at $\lambda_{\mathrm{em}}=$ $426 \mathrm{~nm}$ with progress of reaction time confirms the formation of $\mathrm{OH}$ radicals. A linear characteristic was observed for a plot of the fluorescence intensity versus reaction time. The inset gives the fluorescent spectra at different time intervals in the presence of $\mathbf{N 8}$ in dark conditions (Fig. 10). Superoxide formation was also confirmed using non-fluorescent DHR123 as a ROS tracking agent (ESI, Fig. S7†).

ESI-mass spectral studies were carried out to analyze the intermediates formed during the degradation of methylene blue. The molecular ion peak for MB (without catalyst) was obtained at $m / z=284$ (ESI, Fig. S8 $\dagger$ ). The peak at $\mathrm{m} / z=270$ corresponds to loss of methyl groups from MB. The peaks at $m / z$ $=318-319,293$ and 279 are due to consecutive additions of hydroxyl in the MB molecule (Fig. 11a). The breaking of the MB molecule was suggested by the presence of peaks at $m / z=205-$ $207,146-149$. From the mass analysis the degradation pathway is shown in Fig. 11b. Detection of hydroxylated intermediates in the ESI-MS study also confirmed that photodegradation of MB in the presence of $\mathbf{N 8}$ proceeded through a hydroxyl radical

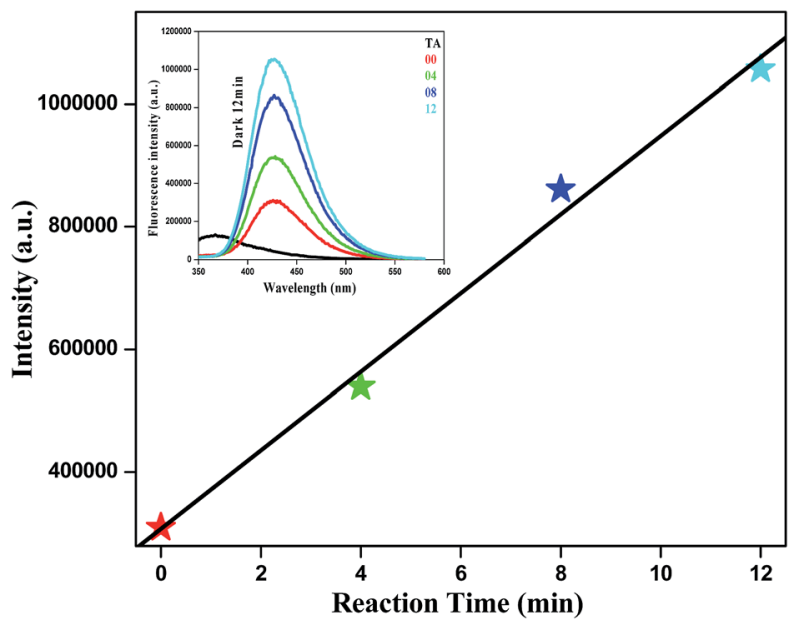

Fig. 10 Fluorescence spectra of aqueous TA solution in the presence of $\mathrm{N} 8$ in the absence of light. mechanism which was also confirmed by the results of TA and DHR123 treatment.

In order to evaluate the active component of the catalysts, various control experiments were performed. Initially, we performed this reaction in the presence of the individual metal sulphides $\left(\mathrm{Ag}_{2} \mathrm{~S}\right.$ and $\left.\mathrm{NiS}\right)$ which were found to be poor catalysts (ESI, Fig. S6b and $c \dagger$ ) in the absence of light. From a literature survey, ${ }^{21}$ it is also evident that $\operatorname{In}_{2} \mathrm{~S}_{3}$ can act as photocatalyst in the presence of visible light for a longer time. No report was found for the same in dark conditions. We also performed this reaction in dark conditions to evaluate the activity of $\operatorname{In}_{2} S_{3}$, and it was found to be poor. This supports the conclusion that the degradation of MB was due to a synergistic effect of the nanocomposites and not due to the individual components. It is believed that the electron storage properties of $\mathrm{Ag}$ helps in shifting of the apparent Fermi level of the composite towards more negative potential and makes it more reductive photocatalyst. This reductive nature of the

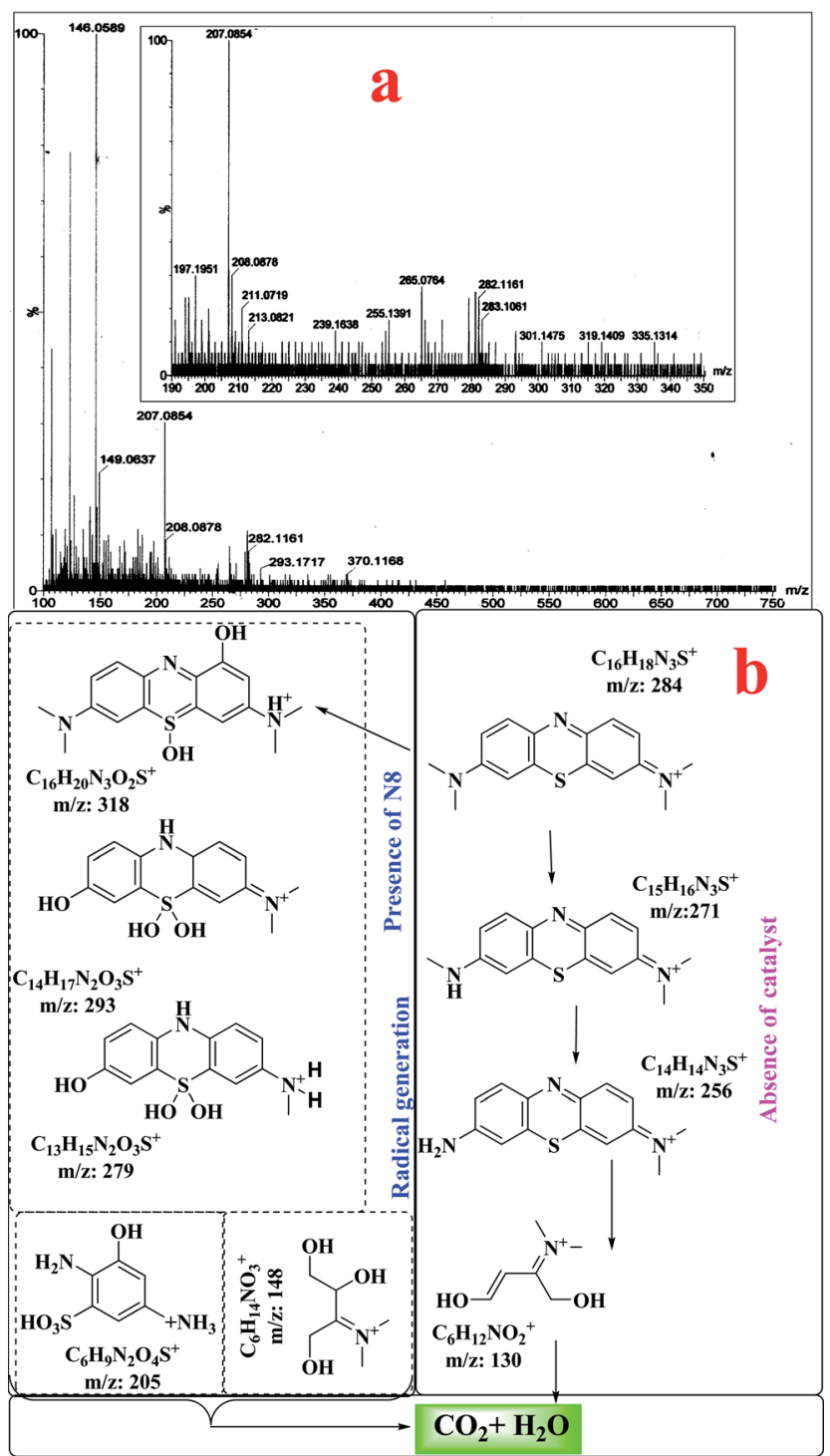

Fig. 11 (a) ESI mass analysis of MB in the presence of N8, (b) formation of intermediates. 


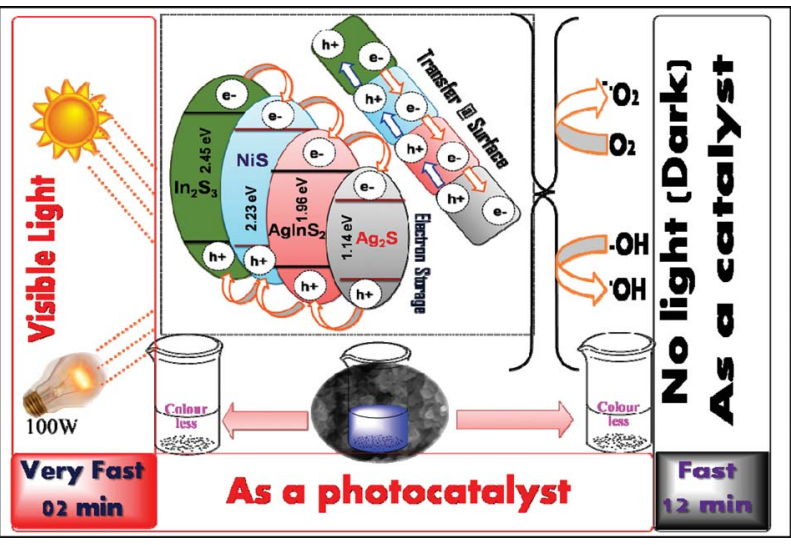

Fig. 12 Photodegradation mechanism of $\mathrm{Ag}-\mathrm{In}-\mathrm{Ni}-\mathrm{S}$ in the presence and absence of light.

photocatalyst supplies electrons even in dark conditions, which are dissipated across the surface resulting in the formation of ROS which is also confirmed from the terephthalic acid treatment. The photo-induced electron-hole pair generation is faster in the presence of different multinary semiconductor chalcogenides, one or of which more may act as co-catalysts in this process. The scavenging of holes in the presence of $\mathrm{S}^{2-} / \mathrm{S}_{n}{ }^{2-}$ redox couples is reasonably effective in scavenging the holes from the nanocomposites to maintain their stability throughout the experiments. $^{22}$

Based on our control experiments and observations for ROS generation, a mechanistic diagram was proposed (Fig. 12), where the electron storage behaviour of silver can promote the formation of electron-hole pairs even in the absence of light. The generation of electron-hole pairs under visible light is faster. The surface transfer process of the electron-hole pairs over the coupled semiconductor nanocomposites makes them more suitable for the generation of ROS. These generated ROS are responsible for the degradation of MB.

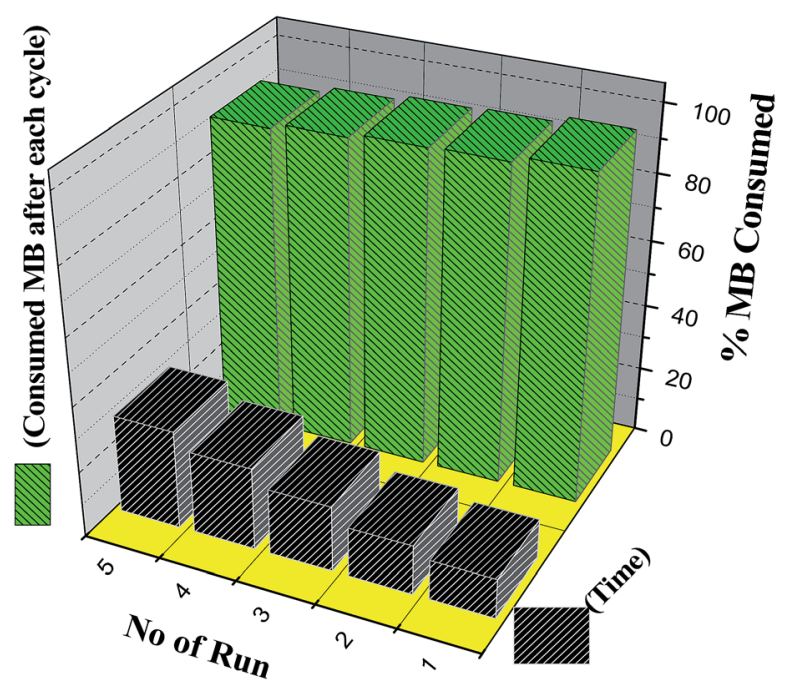

Fig. 13 Photodegradation cycle of $\mathrm{Ag}-\mathrm{In}-\mathrm{Ni}-\mathrm{S}$ (sample N8) in the absence of light.
Finally, reusability of the catalysts was examined in dark conditions for samples N5 and N8 (Fig. 13). After completion of each cycle, the catalyst was collected by centrifugation, washed several times with ethanol and water and finally dried under vacuum and reused for the next run. The recycled catalyst took slightly longer time to decompose $\mathrm{MB}$ completely. We also compared our results with reported $\mathrm{Ag}$ based catalysts (Table S5, ESI $\dagger$ ). It is found that the Ag-In-Ni-S nanocomposites are efficient active catalysts under both dark and visible light conditions. PXRD, TGA, IR and SEM of reused catalysts were compared (Fig. S9, ESI $\dagger$ ) with those of a fresh sample. The results substantiate that there were no structural and morphological changes after five cycles of use.

\section{Conclusions}

We have developed a simple and green protocol for the synthesis of Ag-In-Ni-S nanocomposites using thioacetamide as the sulphur source in water with variation of SDS concentration and temperature.

The XRD analysis showed that Ag-In-Ni-S is a composite of binary and ternary chalcogenides. The FE-SEM and EDX analyses indicated uniform size and elemental distributions in all the samples. XPS analysis confirmed that $\mathrm{Ag}^{+}, \mathrm{In}^{3+}, \mathrm{Ni}^{2+}$ and $\mathrm{S}^{2-}$ are present in the nanocomposites. The wide binding energy range of sulphide clearly indicated the presence of both binary and ternary chalcogenides. UV-vis and DRS reflectance spectra suggested that the samples are capable of absorbing visible light. We explored the catalytic activities via methylene blue degradation under darkness and visible light. The synergistic effect of nanocomposites promotes the generation of ROS for the fast degradation of dye in darkness $(12 \mathrm{~min})$ and under visible light (sunlight: $2 \mathrm{~min}, 100 \mathrm{~W}$ lamp: $4 \mathrm{~min}$ ). The decomposed intermediates were identified with the help of ESIMS analysis. The fast decomposition of MB under light and darkness (day and night) is especially important in the context of waste water treatment targeting the colored effluents of the dye industry, for instance. Moreover, the protocol follows some tenets of "green chemistry" with respect to synthesis steps, solvent used and catalytic applications.

\section{Acknowledgements}

A.M and M.S are thankful to IIT Patna for their research fellowship. The authors are also thankful to Prof. T. Pradeep and P. Gautham for XPS analysis and Department of Science and Technology India for research grant no. SR/FT/CS-093/2009. The authors are thankful to the anonymous reviewers for their constructive suggestions.

\section{Notes and references}

1 A. Fujishima and K. Honda, Nature, 1972, 238, 37-38.

2 (a) Y. K. Lai, J. Y. Huang, H. F. Zhang, V. P. Subramaniam, Y. X. Tang, D. G. Gong, L. Sun, L. Sundar, Z. Chen and C. Lin, J. Hazard. Mater., 2010, 184, 855-863; (b) N. Wang, X. Li, Y. Wang, X. Quan and G. Chen, Chem. Eng. J., 2009, 
146, 30-35; (c) O. K. Varghese, M. Paulose, T. J. LaTempa and C. A. Grimes, Nano Lett., 2009, 9, 731-737; (d) W. Zhao, W. Ma, C. Chen, J. Zhao and Z. Shuai, J. Am. Chem. Soc., 2004, 126, 4782-4783.

3 S. Guo, S. Han, H. Mao, S. Dong, C. Wu, L. Jia, B. Chi, J. Pu and J. Li, J. Power Sources, 2014, 245, 979-985.

4 J. Xia, J. Di, S. Yin, H. Xu, J. Zhang, Y. Xu, L. Xu, H. Li and M. Ji, RSC Adv., 2014, 4, 82-90.

5 (a) C. Zhang, L. Ai, L. Li and J. Jiang, J. Alloys Compd., 2014, 582, 576-582; (b) J. Shua, Z. Wanga, G. Xia, Y. Zheng, L. Yang and W. Zhang, Chem. Eng. J., 2014, 252, 374-381.

6 (a) J. Yu, J. Jin, B. Cheng and M. Jaroniec, J. Mater. Chem. A, 2014, 2, 3407-3416; (b) X. Wanga, W.-C. Peng and X.-Y. Li, Int. J. Hydrogen Energy, 2014, 39, 13454-13461; (c) K. Chang, Z. W. Mei, T. Wang, Q. Kang, S. X. Ouyang and J. H. Ye, ACS Nano, 2014, 8, 7078-7087; (d) I. Kornarakis, I. N. Lykakis, N. Vordos and G. S. Armatas, Nanoscale, 2014, 6, 8694-8703; (e) I. J.-L. Plante, A. Teitelboim, I. Pinkas, D. Oron and T. Mokari, J. Phys. Chem. Lett., 2014, 5, 590-596; (f) Y. Shi, Y. Chen, G. Tian, H. Fu, K. Pan, J. Zhou and H. Yan, Dalton Trans., 2014, 43, 12396-12404; (g) L. Ye, J. Fu, Z. Xu, R. Yuan and Z. Li, ACS Appl. Mater. Interfaces, 2014, 6, 3483-3490.

7 (a) B. Chai, J. Li, Q. Xu and K. Dai, Mater. Lett., 2014, 120, 177-181; (b) L.-Y. Chen and W.-D. Zhang, Appl. Surf. Sci., 2014, 301, 428-435; (c) M. Shi, J. Shen, H. Ma, Z. Li, X. Lu, N. Li and M. Ye, Colloids Surf., A, 2012, 405, 30-37; (d) D. Fu, G. Han, Y. Chang and J. Dong, Mater. Chem. Phys, 2012, 132, 673-681; (e) W. Ming Yan, H. J. Rao, T. Zhi-Wei, L. Wei-Hua and C. Jun, J. Alloys Compd., 2013, 568, 26-35; (f) Y. Fu and X. Wang, Ind. Eng. Chem. Res., 2011, 50, 72107218; $(g)$ Y. Fu, Q. Chen, M. He, Y. Wan, X. Sun, H. Xia and X. Wang, Ind. Eng. Chem. Res., 2012, 51, 11700-11709.

8 (a) Q. Liu, Y. Zhou, J. Kou, X. Chen, Z. Tian, J. Gao, S. Yan and Z. Zou, J. Am. Chem. Soc., 2010, 132, 14385-14387; (b) L. J. Zhang, T. F. Xie, D. J. Wang, S. Li, L. L. Wang, L. P. Chen and Y. C. Lu, Int. J. Hydrogen Energy, 2013, 38, 11811-11817; (c) L. Ren, F. Yang, Y.-R. Deng, N.-N. Yan, S. Huang, D. Lei, Q. Sun and Y. Yu, Int. J. Hydrogen Energy, 2010, 35, 3297-3305.

9 (a) B. Murali, M. Madhuri and S. B. Krupanidhi, Cryst. Growth Des., 2014, 14, 3685-3691; (b) Y. A. Douri, Q. Khasawneh, S. Kiwan, U. Hashim, S. B. A. Hamid, A. H. Reshak, A. Bouhemadou, M. Ameri and R. Khenata, Energy Convers. Manage., 2014, 82, 238-243; (c) R. Lindblad, D. Bi, B.-w. Park, J. Oscarsson, M. Gorgoi, H. Siegbahn, M. Odelius, E. M. J. Johansson and H. Rensmo, J. Phys. Chem. Lett., 2014, 5, 648-653; (d) S. Ito, S. Tanaka, K. Manabe and H. Nishino, J. Phys. Chem. C, 2014, 118, 16995-17000; (e) R. Sahaya, J. Sundaramurthya, P. S. Kumara, V. Thavasi, S. G. Mhaisalkara and S. Ramakrishna, J. Solid State Chem., 2012, 186, 261-267.

10 (a) J. Kolny-Olesiak and H. Weller, ACS Appl. Mater. Interfaces, 2013, 5, 12221-12237; (b) L. Sójka, Z. Tang, D. Furniss, H. Sakr, A. Oladeji, E. Bereś-Pawlik, H. Dantanarayana, E. Faber, A. B. Seddon, T. M. Benson and S. Sujecki, Opt. Mater., 2014, 36, 1076-1082; (c)
H. C. Yoon, J. H. Oh, M. Ko, H. Yoo and Y. R. Do, ACS Appl. Mater. Interfaces, 2015, 7, 7342-7350.

11 (a) A. Deshpande, S. Kelkar, S. Rayalu and S. Ogale, J. Mater. Chem. A, 2014, 2, 492-499; (b) S. Kelkar, C. Ballal, A. Deshpande, S. Warule and S. Ogale, J. Mater. Chem. A, 2013, 1, 12426-12431; (c) M. Moriya, T. Minegishi, H. Kumagai, M. Katayama, J. Kubota and K. Domen, J. Am. Chem. Soc., 2013, 135, 3733-3735; (d) L. Zhang, T. Minegishi, J. Kubota and K. Domen, Phys. Chem. Chem. Phys., 2014, 16, 6167-6174; (e) C. Yang, M. Qin, Y. Wang, D. Wan, F. Huang and J. Lin, Sci. Rep., 2013, 3, 1286; $(f)$ L. Wei, Y. Chen, Y. Lin, H. Wu, R. Yuan and Z. Li, Appl. Catal., B, 2014, 144, 521-527.

12 (a) D. Chakravarty and D. J. Late, $R S C A d v$., 2015, 5, 2170021709; (b) H. Chauhan, M. K. Singh, S. A. Hashmi and S. Deka, RSC Adv., 2015, 5, 17228-17235; (c) H. Peng, G. Ma, K. Sun, J. Mu, H. Wang and Z. Lei, J. Mater. Chem. A, 2014, 2, 3303-3307; (d) I. B. Assaker, M. Gannouni, A. Lamouchi and R. Chtourou, Superlattices Microstruct., 2014, 75, 159-170.

13 (a) B. Hu, L.-H. Wu, S.-J. Liu, H.-B. Yao, H.-Y. Shi, G.-P. Li and S.-H. Yu, Chem. Commun., 2010, 46, 2277-2279; (b) Y. Wen, H. Ding and Y. Shan, Nanoscale, 2011, 3, 4411-4417; (c) Y. Yan, H. Sun, P. Yao, S.-Z. Kang and J. Mu, Appl. Surf. Sci., 2011, 257, 3620-3626; (d) J.-K. Liu, C.-X. Luo, J.-D. Wang, X.-H. Yang and X.-H. Zhong, CrystEngComm, 2012, 14, 8714-8721; (e) Q. Chen, H. Shi, W. Shi, Y. Xu and D. Wu, Catal. Sci. Technol., 2012, 2, 1213-1220; (f) F. Jia, Z. Yao and Z. Jiang, Int. J. Hydrogen Energy, 2012, 37, 30483055; $(g)$ A. Pourahmad, Superlattices Microstruct., 2012, 52, 276-287; (h) Y. Zheng and A. Wang, J. Mater. Chem., 2012, 22, 16552-16559; (i) L. Zhu, B. Wei, L. Xu, Z. Lü, H. Zhang, H. Gao and J. Che, CrystEngComm, 2012, 14, 5705-5709; (j) C. Zeng, B. Tian and J. Zhang, J. Colloid Interface Sci., 2013, 405, 17-21; (k) B. Jiang, Z. Hou, C. Tian, W. Zhou, X. Zhang, A. Wu, G. Tian, K. Pan, Z. Ren and H. Fu, CrystEngComm, 2013, 15, 5821-5827; $(l)$ L. Wang, N. Li, Q. Zhang, S. Lou, Y. Zhao, M. Chen and F. Teng, CrystEngComm, 2014, 16, 9326-9330; (m) D. Marcinkowski, M. Wałęsa-Chorab, V. Patroniak, M. Kubicki, G. Kadziołka and B. Michalkiewicz, New J. Chem., 2014, 38, 604-610; (n) Z. Wei, L. Feng, J. Zhi-Ming, S. Xiao-Bo, Y. Peng-Hui, W. Xue-Ren, S. Cheng, G. Zhan-Qi and L. Liang-Sheng, $J$. Mater. Chem. A, 2014, 2, 13226-13231; (o) Z. Jiang, D. Liu, D. Jiang, W. Wei, K. Qian, M. Chen and J. Xie, Dalton Trans., 2014, 43, 13792-13802; (p) C. Han, L. Ge, C. Chen, Y. Li, Z. Zhao, X. Xiao, Z. Li and J. Zhang, J. Mater. Chem. A, 2014, 2, 12594-12600.

14 (a) J. Li, S. K. Cushing, J. Bright, F. Meng, T. R. Senty, P. Zheng, A. D. Bristow and N. Wu, ACS Catal., 2013, 3, 4751; (b) L. Sun, R. Zhang, Y. Wang and W. Chen, ACS Appl. Mater. Interfaces, 2014, 6, 14819-14826; (c) M. Zhu, P. Chen and M. Liu, ACS Nano, 2011, 5, 4529-4536.

15 (a) M. Anpo and M. Takeuchi, J. Catal., 2003, 216, 505-516; (b) J. W. Wang, B. D. Mao, J. L. Gole and C. Burda, Nanoscale, 2010, 2, 2257-2261; (c) S. In, A. Orlov, R. Berg, F. Garcia, S. Pedrosa-Jimenez, M. S. Tikho, D. S. Wright 
and R. M. Lambert, J. Am. Chem. Soc., 2007, 129, 1379013791; (d) S. Sakthivel and H. Kisch, Angew. Chem., Int. Ed., 2003, 42, 4908-4911; (e) H. Zhang, G. Wang, D. Chen, X. J. Lv and J. H. Li, Chem. Mater., 2008, 20, 6543-6549; (f) S. F. Chen, J. P. Li, K. Qian, W. P. Xu, Y. Lu, Q. X. Huan and S. H. Yu, Nano Res., 2010, 3, 244-255.

16 Q. W. Shu, J. Lan, M. X. Gao, J. Wang and C. Z. Huang, CrystEngComm, 2015, 17, 1374-1380.

17 J. K. Olesiak and H. Weller, ACS Appl. Mater. Interfaces, 2013, 5, 12221-12237.

18 (a) M. Yoon, M. Seo, C. Jeong, J. H. Jang and K. S. Jeon, Chem. Mater., 2005, 17, 6069-6079; (b) M. Ge, L. Liu, W. Chen and Z. Zhou, CrystEngComm, 2012, 14, 1038-1044.
19 J. Krzystek, J.-H. Park, M. W. Meisel, M. A. Hitchman, H. Stratemeier, L.-C. Brunel and J. Telser, Inorg. Chem., 2002, 41, 4478-4487.

20 (a) K. I. Ishibashi, A. Fujishima, T. Watanabe and K. Hashimoto, Electrochem. Commun., 2000, 2, 207-210; (b) S. Singh, A. C. Chakraborty, V. Singh, A. Molla, S. Hussain, M. K. Singh and P. Das, Phys. Chem. Chem. Phys., 2015, 17, 5973-5981; (c) A. Molla, M. Sahu, Y. Kumar and S. Hussain, RSC Adv., 2015, 5, 41941-41948.

21 (a) S. Rengaraj, S. Venkataraj, C.-W. Tai, Y. Kim, E. Repo and M. Sillanp, Langmuir, 2011, 27, 5534-5541; (b) G. Liu, X. Jiao, Z. Qin and D. Chen, CrystEngComm, 2011, 13, 182-187.

22 P. V. Kamat, J. Phys. Chem. Lett., 2012, 3, 663-672 and references cited therein. 